\title{
Live Learning: Online Teaching, Digital Literacy and the Practice of Inquiry
}

\author{
Leo Casey $^{a 1}$, and Michael Hallissy ${ }^{b}$ \\ ${ }^{a}$ Centre for Research and Innovation in Learning and Teaching, National College of Ireland \\ ${ }^{b}$ H2 Learning, Digital Exchange, Crane Street, The Digital Hub, Dublin 8
}

(Received March 2014; final version received September 2014)

\section{Introduction}

There has been significant discussion in recent times around improving the quality of teaching and learning in higher education (Laycock, 2009; Laurillard \& Masterman, 2010; DES, 2010). The Lisbon Strategy (Commission to the Council and the European Parliament, 2006) has framed much of this discussion at a European level with individual countries, such as Ireland, developing their owntargeted strategies to expand and improve higher education (DES, 2010). In the case of Ireland, these strategies specifically mention the need for institutions to provide 'excellent teaching' whether in face-to-face or online settings. Whereas there is a significant body of on-going research conducted around effective teaching in traditional, face-to-face settings in higher education (for example, Bennett \& Barp, 2008, Beetham \& Sharpe, 2007) there is, in recent times, an emerging need for investigations that focus on new contexts for teaching particularly in online synchronous classrooms. Many institutions have invested substantial time and resources in procuring new technology systems to support on-line teaching and in training staff to operate the many varied functions within these technologies. However, there is also a need to go beyond mere functionality and to provide deeper pedagogical support to faculty so they can fully realise the instructional potential of these systems (Kim \& Bonk, 2006; Lee \& Hirumi, 2004). Technological innovations in the area of online teaching lead to new challenges for teachers and educators as new tools are developed and adopted by their institutions. A question for researchers is the extent to which these tools augment or inhibit existing roles and practices in the classroom and to ask how we can conceptualize learning and teaching in such contexts.

The case for considering inquiry learning as the 'telos' or central purpose of classroom practice is presented here. In this way the live on-line classroom is conceived as a communal learning space where teacher and students participate in activities that are enabled, sustained and enriched by the functionality of the technology system.

\section{Online Tutorial Software}

Computer-mediated communication (CMC) technology has evolved in recent years and it is now quite popular in many online higher education courses. CMC has been defined as "communication that takes place between human beings via the instrumentality of computers" (Herring, 1996, p. 1 in

\footnotetext{
${ }^{1}$ Corresponding author. Email: leo.casey@,ncirl.ie

Irish Journal of Technology Enhanced Learning Ireland, 2014. (c) 2014 L. Casey, M Hallissy. The Irish Journal of Technology Enhanced Learning Ireland is the journal of the Irish Learning Technology Association, an Irish-based professional and scholarly society and membership organisation. (CRO\# 520231) http://www.ilta.ie/. This is an Open Access article distributed under the terms of the Creative Commons Attribution 4.0 International License (http://creativecommons.org/licenses/by/4.0/), allowing third parties to copy and redistribute the material in any medium or format and to remix, transform, and build upon the material for any purpose, even commercially, provided the original work is properly cited and states its license.
} 
Rosell-Aguillar, 2007: p. 81). Initially the majority of CMC was asynchronous and used tools such as email, message boards etc., however in recent times there has been a move towards synchronous tools. Initially synchronous CMC (SCMC) was limited to "text chat" but it has now expanded to include both audio and video conferencing. Today there is a growing list of software tools, such as Adobe Connect, AT\&T Connect and Blackboard Collaborate, to allow teachers and learners to interact in real-time online. Typically these interactions are scheduled in advance so that students and teachers attend at the same time - this is why we use the term 'live learning'. These tools create online classrooms where tutors and their students communicate in live interactions, something that heretofore may have been difficult to accommodate. Lyceum technology was one of the earliest SCMC tools designed to replace face-to-face tutorials (Buckingham Shum et al., 2001) within the UK Open University. The technology was developed in-house and was initially trialed in foreign language and business courses. An early review of the Lyceum system captured the challenges it presented to some teachers who felt they were 'deskilled' in this new environment.

We are hearing enthusiastic praise for Lyceum's potential from many tutors and students, but also understandable reluctance from others who feel deskilled in the new medium, who have had poor experiences using it, or who fear that face-to-face meetings may be abolished.

(Buckingham Shum et al., 2001; p. 8)

The introduction of these new tools appears to present challenges for tutors who are often experienced and knowledgeable in face-to-face settings and in using other technologies. There is a need to support faculty in this transition so they are confident and competent in these new spaces.

\section{Challenges faced by teachers in online classrooms}

Teaching online casts teachers in new roles where they will require training and support in how to use the technology effectively. Integrating technology into one's teaching is a complex task (Koehler \& Mishra, 2008) that may require the teacher to rethink how they teach. Typically institutions, in the first instance, tend to focus on providing teachers with the technical skills associated with using the technology (Lee \& Hirumi, 2004; Kim \& Bonk, 2006) often at the expense of developing their pedagogical skills. Undoubtedly teachers require technical knowledge in order to use these tools but it also needs to be balanced with pedagogical knowledge. Ultimately teachers will need to develop their 'professional practice knowledge' (Loughran, 2010) around using these technologies in order to create quality teaching-learning interactions. Loughran defines professional practice knowledge as the 'craft' or 'tacit' knowledge that includes the tips and tricks of using certain tools in practice, while Polany (1967) the inventor of the term, described it as "that which we know but cannot tell" (Eraut, 1994; p. 15). There currently appears to be a deficit of such practical, concrete knowledge to support tutors to create effective live classrooms online using SCMC tools.

There is evidence that the use of such technologies in higher education is now placing demands on teachers to update their skills and competences in order to enhance teaching-learning interactions (Laycock, 2009). Some, such as Laurillard and Masterman (2010), have raised concerns that teachers are not fully utilising these tools and the new opportunities they offer for recasting teaching-learning interactions online. Instead many teachers appear more comfortable transferring existing 'traditional teaching approaches' from face-to-face to online settings (Kim \& Bonk, 2006), despite a growing literature that recommends the need for more active or inquiry led teaching approaches (Conrad, 2007; Hrastinski, 2009; Laurillard \& Masterman, 2010).

Much of this literature acknowledges the social nature of teaching and learning online and calls on teachers to change their practices in order to create more collaborative and co-operative learning activities for their students (McInnerney \& Roberts, 2004). Undoubtedly this places new demands on teachers and requires them to invest time and energy in updating their professional knowledge (Loughran, 2010). Technological developments are happening so fast that institutions often struggle to design timely professional development interventions for their staff. Faced with this constant challenge some believe that teachers, at all levels, need to take more responsibility for their own learning and not wait for their institution to provide such 'training' (Barber, 1996; Mishra \& Koehler, 2006; Laurillard \& Masterman, 2010). It now seems timely for tutors to begin capturing their own 
practice and to reflect on it in a critical way in order for them to share their experiences with colleagues and beyond their institutions.

Within this discourse teachers are viewed as "learning professionals" who take responsibility for developing their skills and professional competences right throughout their careers (Eraut, 1994). If teachers view themselves as 'learning professionals' then they are expected to share and publicise their professional knowledge of working online with their colleagues, something many teachers have been slow to do in the past (Loughran, 2010). As professionals there is an expectation that they take responsibility for their own learning and continually keep up to date with developments in their field. However, there is also a need for better guidance and more user friendly frameworks that will provide teachers with strategies and protocols they can successfully implement to improve learning. There is a growing body of research and literature on competences and strategies for on-line tutors (Collison et al., 2000; Cornelius \& Higgison, 2001; Ko \& Rossen, 2004; Palloff \& Pratt, 2007, 2011; Salmon, $2000,2008,2011)$. The approach suggested here adds to this body of evidence and suggests that further insights can be gleaned from research conducted in other classroom contexts namely, investigations on digital literacy in primary classroom practices.

\section{Literacy and Participation}

In order to see the connection between literacy and learning and thereby appreciate the usefulness of these insights for teaching on-line, three conceptual assertions will need to be accepted. Firstly, we argue that the most useful conception of learning in on-line classrooms is the practice inquiry (Casey \& Bruce, 2011; Bruce \& Casey, 2012); particularly as based on the Inquiry Cycle (Bruce \& Bishop, 2002) which presents a model of the teaching-learning activities involved - we discuss this further below. There is nothing special about the live on-line classroom that connects it to learning as inquiry as such; it is more that the new capabilities and potentialities for learning that are enabled by the technical system facilitate this wider conception of the processes involved. We could discuss learning as inquiry in a traditional classroom context without any reference to technology; such a discussion would emphasise questioning, creativity, participation, communication and reflection - these are the very practices that live, on-line classroom configurations facilitate and encourage.

The second assertion is the centrality of participation as an essential quality of the practice of inquiry. This notion of participation extends beyond other measures such as attendance, interaction or task completion - it is an altogether more complete quality that implies student and teacher activities unencumbered by communication or technical barriers.

The third assertion is that the digital literacy of the classroom is the degree to which participation and inquiry are enabled, sustained and enriched by the media environment. This often involves a perceptual shift from the skills model of digital literacy to be replaced by a situated view emphasizing inquiry as the ultimate goal of instruction in this mode. Furthermore, far from regarding digital literacy as associated with either teacher or student, the alternative identifies literacy as associated with classroom or context rather than individuals. Arising from previous research (Casey, et al., 2009) a new definition for digital literacy in primary school settings was developed:

Digital literacy involves pupils and teachers using digital technology to enable, sustain and enrich all aspects of the inquiry cycle of learning as: ask, investigate, create, discuss and reflect (ibid, p. 7)

The definition centres on ways in which digital media enhance the practice of inquiry in the primary school classroom. We argue that this approach may be extended to include other classroom settings and, in particular, it presents a useful lens through which the learning and teaching practices for live, online classes in higher education may be investigated.

\section{The Practice of Inquiry}


The practice of inquiry is not a modern approach to learning; its theoretical underpinnings are to be found in the writings of Plato, Rousseau and more specifically John Dewey. Dewey (1902) identified natural impulses for learning which he argued could be harnessed and directed in teaching situations. He suggested learning contexts take advantage of these impulses or instincts which he categorized as (i) the social instinct - conversation, personal intercourse, and communication; (ii) the instinct of making - the constructive impulse; (iii) the instinct of investigation - doing things and watching to see what happens; and (iv) the expressive impulse - the desire to extract meaning from experience. Building upon these ideas, the Inquiry Cycle (Bruce \& Bishop, 2002) emphasises a spiral path of inquiry as: asking questions, investigating solutions, creating and connecting, discussing discoveries and experiences, and reflecting on new-found knowledge, and asking new questions. These are condensed to give: ask, investigate, create, communicate and reflect - the constituents of the practice of inquiry in classrooms.

\section{Practice of Inquiry Applied to CMC - Some Emerging Evidence from the Field}

The pedagogic task of nurturing practices such as student discussion, argument, investigation and collaboration in synchronous online classes is not always straightforward. Effective strategies for online teaching and classroom management characterised by the practice of inquiry require a careful balance between student exploration and teacher direction. In these settings learning is initiated and directed by the questions formulated by learners; however generating conditions for the appropriate 'ask' to emerge requires skillful teaching. It is a pedagogy that relies on engaging the learner actively in their own learning and thus competent teachers who are comfortable working with levels of complexity and uncertainty. Teachers who adopt such an approach may perceive themselves as relinquishing control, allowing the learners to dictate the course of their inquiry and this may be challenging for some. We argue however, there are substantial benefits that outweigh the challenges involved. In live, online classes the sense and nature of participation is an important quality. Traditional formats such as lecture and presentation offer little by way of added value for the 'live' classroom. For many subjects there is ample supply of pre-recorded and packaged content. Something extra needs to be involved when students and teachers come together in a virtual classroom. The practice of inquiry encapsulates this extra dimension.

Yet we know from recent research (Hallissy, 2013) that tutors often struggle to create such active learning environments when using SCMC tools. Emerging research on the use of SCMC technologies in an online course has revealed that tutors have found the transition from face-to-face to online challenging. They reported that their existing teaching competences and strategies required additional tweaking when they began using these tools. Though many of their existing strategies and competences did transfer across they also needed to further develop their digital literacy in this new setting. We have selected some comments from one tutor who had already used an inquiry approach in her face-to-face teaching below to illustrate the struggle she had to recreate an inquiry-based classroom online.

She noted:

I had absolutely no experience of it previously, the first time I put on those headphones and said "hello" or "good evening" I was absolutely terrorised [nervous laughter]

However, once she overcame her initial fears she immediately tried to recreate the type of learning environment she had in her face-to-face setting. This tutor, who espoused an active teaching pedagogy, noted that that she was able to draw on her existing teaching skills to re-create an inquiry classroom online. 
I was pleasantly surprised it all happened much much easier than I thought and so I think the strongest thing I found is that my teaching skills are, or if you like my onsite classroom teaching skills, I was able to call on once I just got over the first hurdle of actually doing this online.

Yet she too found that teaching in such settings is different to teaching in a face-to-face classroom (Kim \& Bonk, 2006) and that she needed to adapt her strategies to fit the functions of the SCMC tool she was using.

Certainly the technology doesn't prevent [discussion] they are able to communicate with the technology and it's mainly by writing notes to each other and also by coming in one-voice-at-a-time, but the one-voice-at-a-time only allows one person to speak and so you have twenty listening, whereas when they can write to each other you have, we will say, 10 of the 20 are speaking at any one time.

It appears that this was a learning journey for her, one in which she was cast in the role of a learning professional. Eraut states that, "professionals continually learn on the job, because their work entails engagement in a succession of cases, problems or projects which they have to learn about" (1994, 10). As it is still so new online tutors have no choice but to learn from their experiences and to continually develop their 'tacit knowledge' in relation to using these tools to create engaging online classrooms.

\section{Conclusion}

In this paper we have sought a pedagogical response to the challenge and opportunity of live on-line instruction in higher education. We have argued that SCMC environments present teachers with an array of new possibilities for teaching-learning interactions; however, significant professional development, going well beyond functional training, is required to take full advantage of these. We have made the case for practice of inquiry as an appropriate framework for learning in live, online classroom settings. Within such a framework, participation and its enabling condition 'digital literacy' is an essential quality. The Inquiry Cycle provides a list of elements that characterise the practice of inquiry namely: ask, investigate, create, communicate and reflect. This list may provide a useful template to support teachers in planning and evaluating classroom activities (Casey \& Bruce, 2011). Ironically, learning as inquiry is quite a traditional pedagogy and it is associated more with the play-like activities of the primary classrooms rather than higher education settings. However, higher education is also experiencing a radical shift of emphasis in teaching and learning; a movement that sees open access to streamed content whilst new skills such as problem solving, creativity, collaboration and communication become the sought after outcomes. Where and how will these skills be developed? Live, online classrooms and the practice of inquiry may provide part of the answer.

As we have acknowledged earlier, there is currently a deficit of knowledge in relation to how higher education teachers and tutors are using SCMC technologies. As more and more institutions purchase these systems there is an opportunity to capture the professional practices of faculty in these new environments. The capturing and sharing of such practice will undoubtedly add to the knowledge base of the profession and provide practical 'tips and tricks' on how to enhance student learning. The teaching community is best placed to lead this research agenda and to capture and critique what is taking place in their live classrooms. By engaging in such reflective practice the entire teaching community will learn from the experiences of others and add to the knowledge base associated with developing tutor digital literacies in relation to using SCMC technologies.

\section{References}


Barber, M. (1996). 'New Teachers for a New Century', The Learning Game: Arguments for an Education Revolution (pp. 206-238). London: Gollancz.

Bennett, S. \& Barp, D. (2008). 'Peer observation - a case for doing it online'. Teaching in Higher Education, 13 (5), 559-570.

Beetham, H. \& Sharpe, R. (2007). Rethinking pedagogy for a digital age : designing and delivering elearning. London: Routledge.

Buckingham Shum, S., Marshall, S., Brier, J. \& Evans, T. (March 22-24, 2001). Lyceum: Internet Voice Groupware for Distance Learning. Paper presented at the 1st European Conference on Computer-Supported Collaborative Learning, Euro-CSCL 2001. Maastricht, The Netherlands.

Bruce, B. C., \& Bishop, A. P. (2002). Using the web to support inquiry-based literacy development. Journal of Adolescent \& Adult Literacy, 45(8), 706-714

Bruce, B. C. \& Casey, L. (2012). 'The practice of inquiry: A pedagogical "sweet spot" for digital literacy?'. Computers in the Schools, 29 (1-2), 191-206.

Casey, L., Bruce, B. C., Martin, A., Hallissy, M., Shiel, G., Reynolds, A., Brown, C., \& Coffey, L. (2009). Digital literacy: New approaches to participation and inquiry learning to foster literacy skills among primary school children. Available at: http://hdl.handle.net/2142/9765 [Last accessed March $\left.1^{\text {st }} 2013\right]$.

Casey, L. \& Bruce, B. C. (2010). Sustaining the inquiry cycle: Digital literacy reframed. Paper presented at the Society for Information Technology \& Teacher Education International Conference. San Diego.

Casey, L. \& Bruce, B. C. (2011). 'The Practice Profile of Inquiry: Connecting Digital Literacy and Pedagogy'. E-Learning and Digital Media, 8 (1), 76-85.

Collison, G., Elbaum, B., Haavind, S. \& Tinker, R. (2000). Facilitating Online Learning: Effective Strategies for Moderators. Madison, WI: Atwood Publishing.

Commission to the Council and the European Parliament. (2006). Delivering on the modernisation agenda for universities: Education, Research and Innovation. [Online]. Available at: http://ec.europa.eu/education/higher-education/agenda en.htm. [Last accessed March 1st 2013].

Conrad, D. (2007). 'The Plain Hard Work of Teaching Online: Strategies for Instructors'. In M. Bullen and D. James (Eds), Making the transition to e-learning : strategies and issues Hershey, Pa.; London: Information Science.

Cornelius, S. \& Higgison, C. (2001). The Tutor's Role and Effective Strategies for Online Tutoring. In C. Higgison (ed), Online Tutoring e-Book. Edinburgh and Aberdeen: Heriot-Watt University, The Robert Gordon University.

Department of Education and Skills (DES) (2010). National Strategy for Higher Education: Draft Report. Dublin: Department of Education and Skills.

Dewey, J., (1902). The child and the curriculum; and The school and society. Chicago ; London: University of Chicago Press.

Eraut, M. (1994). Developing Professional Knowledge and Competence London: Falmer Press.

Hallissy, M. (in Press). Building teacher professionalism in teaching-learning interactions between online tutors and learners during synchronous tutorials - a case study from Hibernia College. Dublin: Hibernia College.

Hrastinski, S. (2009). 'A theory of online learning as online participation'. Computers \& Education, $52,78-82$.

Kim, K.-J. \& Bonk, C. J. (2006). 'The Future of Online Teaching and Learning in Higher Education: The Survey Says...'. [Online]. Educause Quarterly. Available at: http://www.educause.edu/EDUCAUSE+Quarterly/EDUCAUSEQuarterlyMagazineVolum/The FutureofOnlineTeachingandLe/157426. [Last accessed March 1st 2013].

Ko, S. \& Rossen, S. (2004). Teaching Online: A Practical Guide. (Second Ed.): Houghton Mifflin, Boston.

Koehler, M. J. \& Mishra, P. (2008). 'Introducing TPCK'. In The American Association of Colleges for Teacher Education (AACTE) Committee (Ed.), Handbook of Technological Pedagogical Content Knowledge (TPCK) for Educators, (pp. 3-28). New York: Taylor \& Francis Group, Routledge. 
Laurillard, D. \& Masterman, E. (2010). 'TPD as Online Collaborative Learning for Innovation in Teaching'. In J. O. Lindberg and A. D. Olofsson (Eds), Online Learning Communities and Teacher Professional Development: Methods for Improved Education Delivery (pp. 230-246). Hershey, PA: Information Science Reference.

Laycock, M. (2009). 'CPD and Critical Learning Communities: you can't have one without the other'. In M. Laycock and L. Shrives (Eds), Embedding CPD in Higher Education (pp. 27-34). London: Staff and Education Development Association Ltd.

Lee, J.-L. \& Hirumi, A. (2004). Analysis of Essential Skills and Knowledge for Teaching Online, Association for Educational Communications and Technology (pp. 534-540). Chicago, IL.

Loughran, J. (2010). What expert teachers do: Enhancing professional knowledge for classroom practice. Oxon, UK: Routledge.

McInnerney, J. M. \& Roberts, T. S. (2004). 'Collaborative or Cooperative Learning? '. In T. S. Roberts (Ed.), Online Collaborative Learning: Theory and Practice (pp. 203-214). London: Information Science Publishing.

Mishra, P. \& Koehler, M. J. (2006). 'Technological Pedagogical Content Knowledge: A Framework for Teacher Knowledge'. Teachers College Record Volume, 108 (6), 1017-1054.

Palloff, R. M. and Pratt, K. (2007). Building Online Learning Communities: Effective Strategies for the Virtual Classroom. San Francisco, CA: Jossey-Bass.

Palloff, R. M. \& Pratt, K. (2011). The Excellent Online Instructor. San Francisco, CA: Jossey-Bass.

Rosell-Aguilar, F. (2007). 'Changing tutor roles in online tutorial support for open distance learning through audio-graphic SCMC'. The JALT CALL Journal, 3 (1-2), 81-94.

Salmon, G. (2000). E-moderating: The Key to Teaching and Learning Online. London: Kogan Pagan.

Salmon, G. (2008). E-moderating: The Key to Teaching and Learning Online. (2nd Ed.). London: RoutledgeFalmer.

Salmon, G. (2011). E-moderating : the key to online teaching and learning (3rd Ed.). London: Routledge. 